\title{
LA CASA DE LAS INFANTAS DE ESPAÑA EN EL REINADO DE FELIPE II: CIERTOS ASPECTOS SOBRE SU ORIGEN, FORMACIÓN Y DIFUSIÓN ${ }^{1}$
}

\section{The House of Infanta of Spain in the Monarchy of Philip II: Some Questions about its Origin, Development and Influence}

\author{
María ALBALADEJO MARTÍNEZ \\ Universidad de Murcia \\ Correo-e: malbaladejo@um.es
}

RESUMEN: A lo largo del siglo xvi, los intentos de reglamentar y establecer un código de conducta para la administración de los espacios y del personal al servicio de la monarquía, se fueron sucediendo dando forma a la estructura de la Casa de la Infanta de España. Isabel Clara Eugenia y Catalina Micaela, hijas de Felipe II y de Isabel de Valois, fueron las primeras infantas en poseer un personal regido por sus propias ordenanzas, creando un modelo que sirvió, a partir de 1579, para la Casa de las infantas posteriores. Conforme a ello y, través de los documentos hallados en la Biblioteca Nacional de Madrid y en los Archivos Generales de Palacio y Simancas entre otros, el presente artículo analiza el origen, formación y estructura de la Casa de Isabel Clara Eugenia y Catalina Micaela, y su influencia en la Casa de sus sucesoras.

Palabras clave: Casa; Habsburgo; etiqueta; monarquía; infantas; Felipe II.

1. Este trabajo se ha realizado dentro del proyecto de investigación Imagen y Apariencia (08723/ PHCS/08), financiado por el Programa de Generación de Conocimiento Científico de Excelencia de la Fundación Séneca-Agencia de Ciencia y Tecnología de la Región de Murcia en el marco del II PCTRM 2013-14. 
ABSTRACT: During the sixteenth century there were many attempts to regulate and establish a conduct code for space management and the staff serving the monarchs and their children, creating the structure of the Infanta of Spain's House. Isabel Clara Eugenia and Catalina Micaela, daughters of Philip II and Isabel of Valois were the first to own staff governed by their own ordinances, creating a very useful pattern, from 1579 to the House of the princesses later in their lineage. Accordingly, and throughout the documents found at the National Library of Madrid and in the General Archives of Simancas Palace, this article discusses the origin, the formation and the structure of the House of the daughters of Philip II and his influence on the princesses of the dynasty of Habsburg.

Key words: House; Habsburg; Protocol; Monarchy; Infants; Philip II.

\section{INTRODUCCIÓN}

A lo largo del siglo Xvi, los intentos de establecer un código de normas para la administración de los espacios y del personal al servicio de los monarcas y de sus hijos, se fueron sucediendo dando forma a la estructura de la Casa de las infantas.

Durante este periodo tuvo lugar el fallecimiento de las reinas Isabel de Valois y Ana de Austria, las hijas de Felipe II quedaron huérfanas de madre, un hecho que propició una mayor atención a ambas, por parte de la corte y el monarca, y que generó la necesidad de reorganizar una Casa que ya no dependía de la de la reina.

La compleja vida palaciega exigía mantener bajo control la función de sus empleados, sus gastos y gajes, especialmente tras la influencia de la Casa de Borgoña en el modelo de servicio castellano que prevalecía desde tiempos de Isabel La Católica en las Casas de las reinas e infantas de España.

Isabel Clara Eugenia y Catalina Micaela, hijas de Felipe II y de Isabel de Valois, poseyeron un personal regido por sus propias ordenanzas. Redactadas en 1579, estas constituyen el primer testimonio escrito con este fin, convirtiéndose en una fuente esencial para profundizar en la función que cumplió la Casa de las infantas durante el reinado de Felipe II y posteriormente en la organización de la Casa del resto de infantas de la dinastía de Habsburgo.

En el presente artículo se ha llevado a cabo un análisis de sus estructuras, ordenanzas y etiquetas a partir de diversas fuentes de la época halladas en la Biblioteca Nacional de Madrid y los Archivos Generales de Palacio y Simancas. El objetivo es conocer la configuración de la Casa de las infantas Isabel Clara Eugenia y Catalina Micaela, el conjunto de sus oficiales y su influencia en la creación de las Casas de las infantas de España durante el reinado de los Austrias. 
Hoy día aún no se dispone de una información completa de las ordenanzas, modelo de servicio y módulos que componían las Casas de las hijas de los monarcas. La mayoría de las noticias concernientes a la etiqueta palatina se centran en el protocolo referido a la vida del rey, el príncipe y la reina, siendo el referente a las infantas el más escaso en cuanto a publicaciones y documentación hallada². El

2. Es muy importante señalar el trabajo de DíAz VALGOMA, D.: Norma y ceremonia de las reinas de la Casa de Austria. Madrid, 1958. Este autor, pionero en el estudio de la etiqueta de las Casas de la Reinas españolas, hace variadas referencias al protocolo de las infantas, tomadas del documento original. Asimismo son importantes las publicaciones relacionadas con la Casa de la Reina Isabel de Valois como las de García Barranco, M.: «La Casa de la reina en tiempos de Isabel de Valois», Crónica Nova, 29, 2002, pp. 85-107; Río BARRedo del, M. J. «De Madrid a Turín: el ceremonial de las reinas españolas en la Corte ducal de Catalina Micaela de Saboya», Cuadernos de Historia Moderna. Madrid, Anejo II, 2003, pp. 97-122; Rodríguez SAlgado, M. J.: «Isabel de Valois. «Casa y vida de una perfecta princesa», Cuadernos de Historia Moderna, 28, 2003, pp. 85-107; CruZ MedinA, V.: «Y porque sale la Reyna a senar acabo, que es mi semana de serbir: La vida en palacio de la Reina Ana, las infantas Isabel Clara Eugenia y Catalina Micaela en las cartas de Ana de Dietrichstein» en LóPEZCordón, M. V., Franco Rubio, G. A. y Fernández Izquierdo, F. (coords.): La reina Isabel y las reinas de España: realidad, modelos e imagen historiográfica. Madrid, 2005, pp. 427-446; MARTíneZ Millán, J. y MARÇAl LOURENÇO, M. P. (coords.): Las relaciones discretas entre las monarquias hispana y portuguesa. Las Casas de las Reinas (siglos XV-XIX), Madrid 2009; Raviola, A. B. y VARALlo, F. (eds.), L'infanta Catalina Micaela. Roma, Carocci, 2013; Labrador Arroyo, F. y López Álvarez, A.: «Las caballerizas de las Reinas en la Monarquía de los Austria: cambios institucionales y evolución de las etiquetas, 1559-1611», Studia Historia. Historia Moderna, 28, 2006, pp. 87-140; Labrador Arroyo, F.: «La influencia de la Casa de Castilla en la organización de la Casa de las Reinas hispanas» en Gambra Gutiérrez, A. y Labrador Arroyo, F. (coords): Evolución y estructura de la casa real de Castilla. Madrid, 2010, pp. 227-262. En relación a este autor son interesantes también otros estudios como: «La evolución del servicio de la mesa en la casa de las reinas hispanas durante el siglo XVI» en Merlotti, A.: Le tavole di corte tra cinque e settecento. Turín, 2013, pp. 125-150: «La casa de la reina Margarita», en Martínez Millán, J. y Visceglia, M. A. (dirs.): La monarquía de Felipe III: la casa del rey. Madrid, 2008, vol. I, pp. 1125-1168; «El sostenimiento económico de la Casa de la reina», en Martínez Millán, J. y Visceglia, M. A. (dirs.): La monarquía de Felipe III: la casa del rey, Madrid, 2008, vol. I, pp. 1258-1322; «La organización de la Casa de Margarita Teresa de Austria para su jornada al Imperio (1666)», en MarTínez Millán, J. y MarÇal Lourenço, M. P. (coords.): Las relaciones discretas entre las Monarquias Hispana y Portuguesa: las casas de las Reinas (siglos $X V$-XIX). Madrid, Polifemo, 2009, II, pp. 1121-1166; «Los oficios de la caballeriza de la reina Margarita de Austria (1599-1611)», Ibero-Americana Pragensia, XL, 2006, pp. 65-90; «Las caballerizas de las reinas en la Monarquía de los Austrias: cambios institucionales y evolución de las etiquetas, 15591611», Studia Historica, Historia Moderna, 28, 2006, pp. 87-140; «La emperatriz Isabel de Portugal, esposa de Carlos V. Casa real y facciones cortesanas (1526-1539)», Portuguese Studies Revierw, 13:1-2, 2005, pp. 135-171; «La Casa de la reina Catalina de Portugal: Organización y luchas de poder (15501560)», Miscelánea Comillas, 61, 2003, pp. 203-252. En relación a la Casa de las reinas hispanas véase también Fernández de Córdova Miralles, A.: La Corte de Isabel I. Ritos y ceremonias de una reina (1474-1504), Madrid 2002; DE LA Torre, A.: La casa de Isabel la Católica. Madrid, 1954, y Cuentas de Gonzalo de Baeza. Tesorero de Isabel La Católica. Madrid, 1955-1956, 2 vols.; MARTínez Millán, J.: «La corte de Felipe II. La casa de la reina Ana», en Riвot, L. (coord.): La monarquía de Felipe II a debate. Madrid, 2000, pp. 164-171; CAÑas GÁlveZ, F. P.: «Las casas de Isabel y Juana de Portugal, reinas de Castilla. Organización, dinámica institucional y prosopografía (1447-1496)», en ZALAmA, M. A.: Vida cotidiana y arte en el palacio de la reina Juana I en Tordesillas. Valladolid, 2003. 
papel simbólico y representativo de las infantas, el hecho de que su Casa estuviera regida e integrada por la de la reina y la propia coyuntura de la época, con hechos como el incendio del Alcázar de Madrid en 1734 y el establecimiento del Archivo de Simancas desde 1572, favorecen que muchos de los documentos, relativos a la formación de las Casas de las hijas de los reyes hispanos, se encuentren dispersos o desaparecidos.

Es por ello que el estudio de la Casa de Isabel Clara Eugenia y Catalina Micaela resulta fundamental. Este ha permitido conocer la etiqueta del personal de palacio dedicado a Isabel Clara Eugenia y Catalina Micaela y algunos de los nombres que componían sus empleados domésticos, deberes y honorarios, cuestiones que se recogen a continuación con objeto de contribuir a la historiografía dedicada a las Casas reales de la monarquía hispánica y a los estudios de corte.

\section{LA INSTITUCIONALIZACIÓN Y REGLAMENTACIÓN DE LA CASA DE LA REINA: MODELO DE SERVICIO PARA LAS INFANTAS DE ESPAÑA}

Las noticias que en general han llegado hasta nuestros días acerca de la Casa de las Infantas de la monarquía hispánica son realmente escasas frente a las halladas en relación a las Casas del rey, la reina y el príncipe. Si bien, es importante señalar que estas han permitido conocer ciertos aspectos de su configuración como sus módulos, modelos de servicio y conjuntos de oficiales.

El conocimiento de la institucionalización y reglamentación de la Casa de la reina resulta por ello muy significativo, ya que en ella se integraba la Casa de sus herederos. «De la cámara de la reina dependían las funciones de educación, crianza de los hijos, y también los pajes de la corte» ${ }^{3}$.

La Casa de la reina gozaba de independencia económica respecto a la del monarca. Gracias a las rentas y tierras que se le asignaban en el momento de su matrimonio, podía sostener a sus servidores masculinos y femeninos, aspecto original y propio de la Casa de las soberanas de la monarquía hispánica. La Casa de la reina quedaba de esta manera sujeta a su control y se equiparaba a la del monarca.

A diferencia de la del rey, la Casa de la soberana carecía de atribuciones políticas en el sentido estricto. No obstante, a menudo algunos núcleos se transformaban en una especie de contrapoder, donde se refugiaban los grupos políticos excluidos o con una religiosidad diferente a la profesada por el monarca. Plataformas de acción política desarrolladas a través de la práctica de la merced, la retribución y la recompensa, constituían cauces indirectos del ejercicio del poder debido a la cercanía con los miembros de la familia real, y ponían de manifiesto la necesi-

3. Fernández de Córdova Miralles, A.: La corte de Isabel I. Ritos y ceremonias de una reina (1474-1504). Madrid, 2002, p. 150. 
dad de controlar y reglamentar el acceso a las personas de la realeza, además del contingente personal y los gastos. De esta manera, la reina se ganaba la lealtad de su servicio «y mantenía el control sobre su propia Casa, recibiendo así mismo compensaciones por parte de su servidumbre» ${ }^{4}$.

La Casa de la reina se organizaba principalmente en torno a una servidumbre encargada de sus cuidados personales y de sus necesidades religiosas en torno a cuatro áreas: la «Casa», propiamente dicha u oficios de boca, la Cámara dedicada a los aspectos más íntimos de las personas reales y distribución de la gracia, la Capilla, destinada a los oficios litúrgicos, y la Caballeriza.

Por el contrario, la Casa del rey, según Martínez Millán era «un espacio clave en la distribución del poder político durante las Edades Media y Moderna» ${ }^{5}$. En ella el soberano ejercía su autoridad en el conjunto doméstico y a su vez, en el ámbito político ${ }^{6}$. Esta abarcaba tres grandes áreas: el gobierno de la monarquía, integrado por los Consejos, tribunales y sus ministros; el gobierno de las Casas reales y, finalmente, el séquito cortesano ${ }^{7}$. La corte era un grupo de hombres que acompañaba al monarca y un ámbito geográfico de contornos fluidos, cuya relación se fundamentaba, según Fernández de Córdova, «en una mezcla de camaradería y autoridad patriarcal denominada familiaritas. La corte debía satisfacer las necesidades del monarca en sus tres vidas: la espiritual, la natural y la civil» ${ }^{8}$.

Igualmente, a diferencia de la del rey, en la Casa de la reina predominaban más las mujeres que los hombres en su servicio y, lo más importante antes mencionado, en ella se integraba la Casa de sus descendientes?.

Personajes de la alta nobleza castellana, con acceso directo a la reina y a sus hijos, gobernaban su casa, de ahí que el personal fuese ordenado jerárquicamente en cada uno de los módulos, que componían su estructura, obedeciendo un protocolo. El mayordomo mayor era el principal responsable de la Casa, en su conjunto, y del personal de servicio, seguido por la camarera mayor, por norma general una viuda de la alta nobleza, que gobernaba el personal y la esfera femenina de la Casa de la reina, «compuesta por las damas, dueñas, camaristas, mozas de retrete, lavanderas y criadas particulares ${ }^{10}$. A ellos se les sumaba un ingente número de

4. García Barranco, M.: «La Casa de la reina en tiempos de Isabel de Valois», Crónica Nova. 29, 2002, p. 94.

5. Martínez Millán, J. y Fernández Conti, S.: La monarquía de Felipe II: la Casa del Rey. Madrid, 2005, p. 49.

6. RAE. Diccionario de Autoridades. Madrid, 1990. Asimismo, cuando se habla de la Casa de Austria o de Habsburgo, este vocablo adquiere un nuevo significado sinónimo de dinastía, en cuanto se usa para designar al conjunto de miembros de la monarquía que la conforman y su pertenencia.

7. Fernández de Córdova Miralles, op. cit., p. 28.

8. Idem, p. 21.

9. Martínez Millán y Fernández Conti, op. cit., p. 1055.

10. García Barranco, op. cit., p. 97. 
empleados divididos en oficiales mayores, con acceso directo a la persona real, y oficiales menores encargados de las labores domésticas, tales como el maestre sala, guarda de damas, tapicero, sastres, guardajoyas etc.

La servidumbre de la Casa Real se organizaba entonces siguiendo un estricto orden y control de labores que suponían distintos grados de retribución y prestigio imponiéndose una verdadera jerarquía. Igualmente, existía una diferencia de género «además de distinguirse entre los sirvientes del rey y los de la reina, las mujeres al servicio de la soberana nunca copaban los cargos superiores del escalafón dentro de la Casa de la Reina, sino que eran hombres los que ocupaban tales puestos, dirigiendo toda la organización de la Casa el mayordomo mayor» ${ }^{11}$.

Los cargos principales dentro de la Casa de la Reina (confesor, limosnero, mayordomo mayor, ambas camareras, y camaristas) eran nombrados por el rey y la reina, según su caso. Para el resto de oficios, el encargado de las designaciones era el mayordomo mayor previa consulta al rey.

La función de cada uno de los oficiales era regida a su vez por un protocolo, fundamental para el buen funcionamiento de la Casa. La etiqueta, definida por Francisco López Nieto como «el ceremonial de los estilos, usos y costumbres que se deben observar y guardar en las casas reales y actos públicos solemnes» ${ }^{12}$, fue un conjunto de reglas cuyo objeto era regular la vida de la monarquía.

En España, las ordenanzas más antiguas dirigidas a la Casa de la reina quedaron determinadas durante la Edad Media, en tiempos de la soberana María de Molina. Durante su reinado se produjo la organización institucional de la Casa de Castilla como modelo de servicio para la Casa de la reina, quedando desde entonces configuradas las líneas maestras de la organización de la Casa de las reinas e infantas hispanas ${ }^{13}$.

Este proceso de asentamiento e institucionalización de la Casa de Castilla como prototipo para la reina se vio favorecido por la llegada de la dinastía Trastámara. Cuando Juana I, hija de los Reyes Católicos, tomó en matrimonio a Felipe I de Habsburgo, como heredera del reino de Castilla, mantuvo muchos de sus oficiales y la reglamentación castellana en su Casa.

Igualmente, su hija María de Trastámara, casada con Manuel I de Portugal, mantuvo y conservó los usos castellanos. Cuando María falleció, la emperatriz Isabel, esposa de Carlos V, heredó gran parte de su servicio y de las normas castellanizadas de la Casa de su madre, favoreciendo así la continuación de sus

11. Idem, pp. 97-98.

12. LÓpez Nieto, F.: Honores y protocolo. Madrid. 2006, p. 22.

13. LabRADOR ARRoyo, F.: «La evolución del servicio de la mesa en la casa de las reinas hispanas durante el siglo XVI», en MerLotTI, A.: Le tavole di corte tra cinque e settecento. Turín, 2013, pp. $125-150$. 
fórmulas, junto con otras propias de la portuguesa, cuya influencia se manifestó especialmente en el servicio a la mesa, creando un modelo a imitar para las Casas de las reinas e infantas posteriores ${ }^{14}$.

En el siglo Xvi, las Casas de las reinas hispanas quedaban organizadas y regidas aparentemente por el protocolo castellano, siguiendo el patrón impuesto por la Casa de la emperatriz Isabel de Portugal, no obstante la influencia de otros estilos vigentes en la corte eran palpables en la Casa de la soberana. Junto al protocolo castellano se conservaron ciertas fórmulas de las etiquetas portuguesa y borgoñona.

No hay que olvidar que el protocolo borgoñón se dio a conocer en la corte castellana como modelo de servicio de Felipe I de Habsburgo. Cuando en 1507:

la situación mental de Juana propició que su marido reclamase ante su suegro, Fernando el Católico, su derecho a gobernar Castilla y con el apoyo de grupos sociales castellanos disidentes del Católico, consiguió ejercer como rey (...), el reino castellano fue regido por un monarca cuyo modelo de servicio era la Casa de Borgoña en el que estaban integrados los principales personajes de las elites flamencas, mientras que la Casa de Castilla quedaba relegada a servir a la reina, que no participaba en política (...) A partir de entonces, el servicio y estructura de las casas de las reinas de la Monarquía hispana fue la de Castilla y a este modelo se recurrió para realizar o para justificar cualquier reforma que se llevó a cabo en fecha posterior, mientras que la casa de los reyes fue la de la dinastía a la que pertenecía el monarca; esto es, a partir de 1517, tras la subida al trono de Carlos, la Casa de Borgoña ${ }^{15}$.

Felipe II llevó a cabo un intento de trasladar estas reglas al servicio de la Casa de Isabel de Valois pero el contingente personal que éstas exigían, las concesiones de tipo económico que excedían con creces las asignaciones anuales de la soberana y su licencia en cuanto a que su mujer mantuviese parte de su séquito francés,

14. Durante las comidas, la reina era servida por tres damas arrodilladas mientras sus pajes portaban y traían las viandas. Véase el siguiente texto Hordenanzas y etiquetas que el rey nuestro señor don Pelipe segundo rey de las Españas mando que guardasen por los criados y criadas de la real cassa de la reyna nuestra señora, dadas en treinta y uno de diziembre de mil quinientos y setenta y cinco años. y refrendadas por su secretario de estado Martín de Gaztelu, Archivo General de Palacio [en adelante AGP], Sección Histórica, caja 49, exp. 3: «Sírvese al estilo de Portugal; es a saber, que están apegadas a la mesa tres damas y puestas de rodillas, la una que corta y las dos que sirven, de manera que el manjar traen hombres y le sirven damas. Todas las otras damas están allí presentes en pie y arrimadas, no callando sino parlando, no solas sino acompañadas; así que las tres dellas dan a la Emperatriz de comer y las otras dan bien a los galanes que decir. Autorizado y regocijado es el estilo portugués; aunque es verdad que algunas veces se ríen tan alto las damas y hablan tan recio los galanes, que pierden su gravedad y aún se importuna Su Magestad».

15. Labrador Arroyo, F.: «La influencia de la Casa de Castilla en la organización de la Casa de las Reinas hispanas» edición digital en $<$ http://www.academia.edu/3073568>, pp. 5-6. [Consultada el 27 de enero de 2014]. 
generaron tales gastos que Felipe II tomó la decisión de mantener la estructura y modos de la Casa de Castilla ${ }^{16}$.

Cuando Isabel de Valois llegó a Toledo en 1560, Felipe II planteó una reforma de su Casa, para reducir la influencia francesa, y decidió mantener la reglamentación de la Casa de Castilla para la reina de acuerdo a los intereses de las facciones cortesanas ${ }^{17}$.

No obstante, a pesar de que en ellas se mantuvo la estructura impuesta por la etiqueta castellana, «la influencia del modelo borgoñón comenzaba a visualizarse en algunos departamentos: capilla y caballeriza y en determinados servicios: mesa, principalmente» ${ }^{18}$. De esta manera, las estructuras cortesanas borgoñonas y castellanas se combinaron en la prestación de servicios.

El traslado de la corte a Madrid en la primavera de 1561 también favoreció la convivencia de la Casa de Castilla y la Casa de Borgoña. El Alcázar, convertido en sede permanente y principal de la familia real desde dicho año, hizo desaparecer el sistema de corte itinerante y propició el nacimiento de un nuevo concepto de vida cortesana que influyeron en la distribución y disposición de las Casas reales. Felipe II emprendió una serie de mejoras y reformas para adaptar el edificio medieval a sus nuevas necesidades. Comenzó a determinar y habilitar los salones para la reina y para sus hijos, «debajo del Cuarto de la Reina, el de los príncipes e infantes, de pocas estancias y ordinariamente decorados ${ }^{19}$ y tomó diversas iniciativas para reglamentar y organizar la Casa de Isabel de Valois, la primera soberana en residir en palacio inmediatamente después de establecer el sistema de corte permanente.

16. García Barranco, op. cit., p. 96. La Casa de Isabel de Valois «estaba conformada, casi en exclusiva, por servidumbre francesa a su llegada a España en 1560. Catalina de Médicis fue la encargada de formar la Casa de su hija Isabel para su ida a la Corte española. Sin embargo, Isabel tuvo que despedir a parte de su personal y enviarlo de vuelta a Francia, pues era deseo de Felipe II que la Casa y servidumbre de su mujer no fuese toda exclusivamente francesa, sino que entraran también a servir en ella damas y oficiales españoles. Se aducían, como razones para tal incorporación, la necesidad de que la nueva reina aprendiese la lengua y costumbres del país en el que tenía que vivir y reinar. Pero lo cierto es que el despido del servicio de origen de la reina era conveniente por razones políticas: evitar influencias externas sobre ella, cauces informales del poder por su misma proximidad al monarca».

17. Tampoco se puede olvidar además las reiteradas solicitudes de las Cortes castellanas de 1555 y 1558 que reclamaban que la Casa del Príncipe don Carlos y de la futura reina se pusiese de acuerdo a la tradición castellana.

18. Labrador Arroyo, F.: «La influencia de la Casa de Castilla...», op. cit., pp. 8-9.

19. ChecA, F.: El Real Alcázar de Madrid. Dos siglos de arquitectura y coleccionismo en la corte de los reyes de España. Madrid, 1994, p. 144. Cuando la construcción de la fachada de Gómez de Mora en 1609 permitió la creación de varias salas, los infantes pasaron a ocupar la fachada oriental y la torre Bahona, en el ángulo noroeste en 1629. Las estancias se conectaban con las habitaciones de la reina por medio de un pasadizo que recorría la fachada y un mirador en la zona más alta compuesto por arcos de medio punto. 
Este hecho, junto al incremento del número de oficiales de las Casas y de sus gastos, llevó a Felipe II a plantear una serie de instrucciones y normativas de carácter general, hacia 1563 y 1564, para determinar los gajes y raciones de sus oficiales. No obstante, lo referente a algunos módulos y secciones de la Casa, como la caballeriza y el servicio a la mesa, no se dejaron por escrito, según Labrador Arroyo por «la contaminación de la influencia borgoñona» ${ }^{20}$. Asimismo, la capilla se redujo y paso a ser un oratorio siendo muchos de sus oficiales los pertenecientes a la Casa del rey.

Como bien señala Labrador Arroyo se trata de «una época de tentativas y pruebas, en donde, probablemente bajo la influencia de los cambios que se operaban en la casa del rey, se fue configurando una etiqueta y un ceremonial específico, teniendo siempre presente el modelo castellano» ${ }^{21}$.

Isabel de Valois falleció en 1568 y las ordenanzas de su Casa nunca llegaron a dejarse por escrito, de ahí la importancia de las noticias halladas en el Archivo General de Simancas sobre ella. No obstante, las circunstancias que rigieron la reglamentación de la Casa de Isabel de Valois fueron imprescindibles para la institucionalización de la Casa de sus hijas, así como de la reina Ana de Austria. En este sentido, las fuentes acerca de la Casa de Isabel desde el año en el que nació su primera hija, 1566, hasta la muerte de la soberana, son fundamentales para conocer la Casa de las infantas en sus primeros años de vida.

\section{La casa de las infantas Isabel Clara Eugenia y Catalina Micaela}

\subsection{Sus ordenanzas}

Al poco de nacer Isabel Clara Eugenia, el 12 de agosto de 1566, y Catalina Micaela, un año más tarde, el 10 de octubre de 1567, se habilitó una pequeña Casa para sus cuidados dentro de la Casa de la reina ${ }^{22}$. Se trataba de una extensión de la Casa de la monarca más sencilla y dependiente de ésta. Compartían gran parte del personal «salvo determinados cargos, como las dueñas, nodrizas y ciertos criados, el resto de mujeres (en el caso de las infantas) pertenecían ya a la Casa

20. Labrador Arroyo, F.: «La influencia de la Casa de Castilla...», op. cit., p. 9. Cuando se tomó Madrid como asentamiento definitivo para la corte en 1561, desde 1563 a 1564, se procedió a la disposición de unas normas para la Casa de reina que en el caso de la caballeriza no llegaron a formularse hasta verse concretadas en 1575.

21. Idem, p. 10.

22. Rodríguez Salgado, op. cit., p. 58. 
de su madre, de donde se desgajaron, como personas de confianza, para cumplir con las tareas de cuidado de las hijas de los Reyes» ${ }^{23}$.

A falta de unas ordenanzas dictadas, las disposiciones halladas desde 1566 a 1570 giraban en torno a los gajes y raciones que su personal debía de recibir, especialmente a raíz de la muerte de la soberana. Hacía 1568 muchos de los oficiales de la Casa de Isabel de Valois quedaron relegados de sus cargos tras el fallecimiento de la reina. La Casa de Isabel de Valois se disolvió quedando la Casa de las infantas como una única Casa. Para velar por sus cuidados, la Casa de Isabel Clara Eugenia y Catalina Micaela conservó parte de los oficiales que pertenecieron a la Casa de su madre y algunos también del fallecido príncipe Carlos ${ }^{24}$. Desde 1568 hasta 1570 tuvieron lugar cambios desde el punto de vista de su servidumbre.

Con la llegada a la corte española de Ana de Austria, el 26 de noviembre de 1570, la Casa de las infantas vivió importantes modificaciones. Debido a la corta edad de ambas, su Casa fue de nuevo integrada en la de la reina, asistiendo a una serie de renovaciones de algunos de los oficiales que ocupaban los cargos más importantes. Antonio de la Cueva, marqués de Ladrada, del círculo del cardenal Espinosa, fue mantenido en el cargo mayordomo mayor de la Casa, sin embargo el aya y la camarera mayor fueron sustituidas para garantizar la lealtad hacía la nueva soberana ${ }^{25}$.

Asimismo, Felipe II planteó la creación de unas etiquetas para la Casa de Ana de Austria que a falta de varios detalles funcionaron desde su llegada. Según especifican los documentos solo faltaban por detallar ciertos aspectos del servicio de la mesa a las infantas. El texto dice así:

Hauiendo don Antonio de la Cueva y yo tratado en cumplimiento delo que Vuestra Magestad mandó lo que toca a dónde y cómo la guardamenor de las damas de las señoras infantas, y considerando que por lo que se ha entendido de doña María de Aragón y doña Leonor de Ayala y Christóual de Robles y Vicente Álvarez, no parece que en ningún tiempo la guarda menor houiesse comido con las damas y que mandar que coma agora causaría quexa y juizio dello, se podría tomar un medio para escusar esto y que se consiga el fin que se pretende por la buena orden y recato con ques razón estén las damas y es que al cabo y junto a la mesa dellas se pusiesse un bufetillo pequeño en que coma la guarda menor sola y que se le dé del mismo plato de las damas y que la siruan los officiales dellas y desta manera no se podrá dezir que come con ellas y estará ala mira de todo lo que se dirá y hará. Vuestra

23. García Barranco, op. cit., p. 106.

24. Amezúa y Mayo, A.: Isabel de Valois, reina de España (1546-1568): Estudio biográfico. Madrid, 1949, p. 96.

25. Véase el siguiente apartado del texto. 
Magestad mandará lo que será seruido que solo este punto falta por resoluer para que se despachela instrucción de la casa de las señoras infantas ${ }^{26}$.

Varios pudieron ser los motivos que llevaron a Felipe II a plantear la redacción de estas normas aprobadas en 1575. Era imprescindible controlar los gastos, obligaciones y privilegios del personal, así como el acceso a la reina. Los gastos generados por la Casa de Isabel de Valois pusieron de manifiesto esta necesidad. Su numeroso personal y los caprichos de la reina, tales como mantener algunos miembros de su corte francesa, o poseer músicos de cámara con plaza, fueron cuestiones que dispararon la economía de su Casa, además de propiciar la existencia de una camarilla de influencias alrededor de la reina que Felipe II no podía controlar ${ }^{27}$.

Para evitar las vicisitudes que surgieron en la Casa de Isabel de Valois, Felipe II mandó licenciar la Casa que acompañaba a Ana de Austria nada más llegar a la frontera de los Países Bajos. De esta manera, los principales oficios fueron asignados entre altos miembros del partido castellano que gozaban de la confianza del rey.

El aspecto económico también era fundamental, aún más cuando hacía 1575 la Hacienda Real se declaró en bancarrota y procedió a la suspensión de pagos de sus deudas generadas tras los conflictos bélicos en los Países Bajos y el avance de los turcos por el Mediterráneo.

Escoger un personal para servir a la reina y a sus hijas, reglamentar sus funciones, establecer sus salarios y controlar los gastos de la Casa, eran asuntos que quedaron fijados en la redacción de las Hordenanzas y etiquetas que el Rey Nuestro Señor don Felipe segundo rey de las Españas mando que guardasen por los criados y criadas de la real Cassa de la Reyna Nuestra Señora, dadas en treinta $y$ uno de diziembre de mil quinientos y setenta y cinco años. Y refrendadas por su secretario de estado Martín de Gaztelu².

Este manuscrito, conservado en el Archivo General de Palacio, estaba destinado a regir la Casa de Ana de Austria en conjunto, así como la de las infantas, infantes y príncipe ${ }^{29}$. Considerado el primer escrito destinado a gobernar la Casa de una reina de la monarquía hispánica, este establecía las normas de la Casa en

26. Archivo Histórico Nacional [en adelante AHN], Consejos, leg. 15.189, doc. 5. Gaztelu a Felipe II, 11 de enero de 1570. Recogido del texto de LABRADOR ARroyo, F.: «La influencia de la Casa de Castilla...», op. cit., p. 11.

27. Ibidem.

28. AGP, Sección Histórica, caja 49, exp. 3.

29. Río Barredo del, M. J. «De Madrid a Turín: el ceremonial de las reinas españolas en la Corte ducal de Catalina Micaela de Saboya», Cuadernos de Historia Moderna, Anejo II. Madrid, 2003, p. 106. 
todo su conjunto, casa, cámara, capilla y caballeriza, y tenía por objeto «controlar el acceso a la reina y evitar los excesos anteriores» ${ }^{30}$, como ha quedado dicho.

Para ello, estas limitaban la entrada a las estancias más íntimas de la reina y a los espacios públicos y semipúblicos. También establecía ciertas restricciones, destinadas a controlar el acompañamiento de la soberana, intentando excluir la presencia de otros varones en sus esferas cotidianas. Se preservaba así la honra de la reina, siempre acompañada por sus damas, y la castidad y el honor de estas mujeres que debían abandonar la corte para contraer un matrimonio acorde con su linaje $\mathrm{e}^{31}$.

Igualmente, este texto regulaba el acceso a los herederos al trono y establecía sus cuidados. La Casa de las infantas Isabel Clara Eugenia y Catalina Micaela, los infantes Carlos Lorenzo y Diego Félix y el príncipe Fernando, era una sola estructura que formaba parte de la de la reina, con quien compartían parte de su servidumbre salvo algunos cargos exclusivos de su servicio. Este el caso del aya, uno de los cargos principales.

Las ordenanzas hacían referencia a sus deberes y funciones. El aya debía «tener mucho cuidado de su criança y Buena Institución y costumbres así en lo espiritual como en lo demás» ${ }^{32}$. Cumplía la función de permanecer junto a

30. Rodríguez Salgado, op. cit., pp. 71-98. De ahora en adelante, todas las visitas de la reina se harían dentro de los horarios designados para ello. Solo se podían realizar cuando los porteros ocupasen la puerta, y no «a oras extraordinarias y prohividas». Igualmente, las damas ya no tenían licencia para entrar y salir con tanta libertad de las salas más íntimas de la reina y de los espacios públicos y semipúblicos.

31. Ibidem. Otros pasatiempos favoritos de la reina, la danza y la música eran también privados. No obstante se admitían observadores y participantes con cierta frecuencia. A partir de 1570 se ordenó que «cuando la reina dançare retirada, no entrará sino el mayordomo mayor» o su sustituto. Se intentaba excluir a otros oficiales varones, incluso el Caballerizo Mayor, quién «lo escusará las vezes que pudiere». Se admite que debían estar presentes las guardas de damas pero, a no ser que se les llamase para un servicio especifico, los reposteros de camas [sic., será cámara] no debían entrar tampoco a la sala donde se practicaba la danza. Ahora bien, si estaba presente el maestro de danza era imprescindible que estuviesen presentes otros oficiales principales, pues lo normal era que fuese acompañado por músicos.

32. Hordenanzas y etiquetas que el rey nuestro señor don Pelipe segundo... AGP, Sección Histórica, caja 49, exp. 3. Estas reglas, elaboradas durante cinco años son de suma importancia porque fueron las primeras etiquetas que se establecieron por escrito para una reina, desde la época de Isabel la Católica, convirtiéndose en el protocolo definitivo de las soberanas posteriores. Así lo reflejan las palabras del Marqués de Santa Cruz, con motivo del fallecimiento de la reina Margarita de Austria, contenidas en el siguiente texto: «Cumpliendo con lo que V. Majestad se sirve de mandar en la resolución de esta consulta, he hecho reconocer los exemplares que puede aver de casos semejantes a este i lo que se ha podido hallar en los libros es la copia inclusa de la cédula que se despacho al Marques de Velada quando murió la señora Reyna Doña Ana que en sustancia es la mesma que se dio al Duque de Lerma. Pero del tiempo de la señora Reyna Doña Ysabel no se halla nada ni parece que lo puede aver porque no hubo casa de la Reyna hasta el año 1575 que se formo la que se puso a la señora Reyna D.a Ana. En Madrid a 25 de octubre de 1644». 
las infantas, infantes y príncipe salvaguardando con su presencia su seguridad y bienestar. Especialmente, a las horas de sus comidas, cenas, acostar, levantarse e, incluso, cuando el maestro les daba la lección, procurando que fuesen atendidos con la reverencia que les correspondía. Cuando era necesario debía dormir en sus aposentos y si, por cualquier motivo, había de ausentarse, escogía una dueña de honor para que hiciese esta labor ${ }^{33}$.

En general, estas normas se centraban en determinar todo lo relacionado con los cuidados y necesidades de los hijos del monarca Felipe II, especialmente de aquello concerniente a la Cámara y las comidas ${ }^{34}$.

Hasta 1579, las infantas compartieron Casa con sus hermanos formando esta parte de la estructura de la Casa de la reina. A partir de dicha fecha, cuando las infantas contaban con trece y doce años de edad, fueron expedidas las etiquetas que iban a regir su propia Casa. En Europa «este era un privilegio reconocido tanto a infantes y príncipes como a infantas y princesas. Además, les hacía visibles en el juego de las relaciones sociales, pues les confería un determinado status» ${ }^{35}$. No se puede obviar que Isabel Clara Eugenia y Catalina Micaela eran la esperanza sucesoria de Felipe II, especialmente cuando en 1579 Felipe II vio morir a dos de sus herederos, el príncipe Fernando y el infante Carlos Lorenzo. Es lógico que, ante la precaria salud de sus descendentes, nacidos de su matrimonio con Ana de Austria, el monarca estuviese pendiente de los cuidados y servicio de las infantas. Tal vez aún más, tras su proyecto de abandonar España para reclamar el trono de Portugal. Tras la muerte sin descendientes en 1578 del rey Sebastián I, es posible que Felipe II pensase en la importancia de reglamentar e institucionalizar la Casa de las infantas, ante su marcha ${ }^{36}$.

Conforme a ello, en 1579, Felipe II ordenó a su secretario, Martín de Gatzelu, expedir las etiquetas de la Casa de Isabel Clara Eugenia y Catalina Micaela, bajo el título La orden que es nuestra voluntad guarden los Criados y Criadas de las serenisimas Ynfantas mis muy caras, y muy amadas Hijas en lo que toca al servicio, uso y ejercicio de sus oficios, y los gajes y raciones que cada uno de ellos ba de tener en cada un año de los que sirvieren, de que han de comenzar a gozar desde principio de Julio de este presente año de mil quinientos setenta y nueve en adelante ${ }^{37}$.

33. Las dueñas de honor habían de tener cuidado de permanecer siempre junto a las infantas, especialmente en ausencia de la camarera mayor y aya, momento en el que habían de suplir lo que tocaba a su servicio, guardando siempre la antigüedad.

34. Labrador Arroyo, F. y López Álvarez, A.: «Las caballerizas de las Reinas en la Monarquía de los Austrias: cambios institucionales y evolución de las etiquetas, 1559-1611» en Studia Historia, Historia Moderna, 28, 2006, pp. 87-140.

35. García Barranco, op. cit., p. 106.

36. BUCETA, E.: Relación de la Junta convocada por Felipe II el 24 de febrero de 1579 para tratar de su pretensión a la Corona de Portugal. Alicante, 2011.

37. Biblioteca Nacional de Madrid [en adelante BNM], Mss. 18720/1.38. 
De acuerdo a estas ordenanzas quedó institucionalizada y reglamentada la Casa de las infantas, siguiendo los modos de la Casa de Castilla, conforme a la Casa de las reinas hispanas. Al igual que a las ya citadas etiquetas de la Casa destinadas a regir la Casa de Ana de Austria, las ordenanzas de 1579 determinaban las labores y gajes de cada uno de los oficiales de la Casa, en cada uno de sus módulos: Casa, Cámara, Capilla y Caballeriza. Las infantas eran servidas a la manera de «dos reinas» por un personal cuyo modelo de servicio perduró hasta el final del régimen moderno.

Ahora bien, a diferencia con las etiquetas de 1575 destinadas a gobernar la Casa de la reina, las ordenanzas de 1579 iban dirigidas a una Casa cuyos departamentos se presentaban más reducidos. En ellas no se describen la función de algunos oficios que si aparecen en las etiquetas de la Casa de Ana de Austria. Es el caso del secretario, tesorero, cuya función la llevaba a cabo el grefier, escuderos de a pie, enfermero, enfermera, escribano de cámara, pajes, guardajoyas y guardarropa. No obstante, esto no significa que estos empleados no sirvieran en su casa, ya que algunos como los dos últimos sí aparecen en las relaciones de gastos y cuentas de la Casa de Isabel Clara Eugenia y Catalina Micaela.

Igualmente, al resto de Casas reales, la servidumbre se establecía de forma jerarquizada. La Casa era dirigida por el mayordomo mayor y bajo su servicio se hallaban los gentiles hombres de la boca, gentiles hombres de la Casa, mozos y ayudas de cada oficio. Bajo su dirección se encontraba también uno de los cargos principales, el grefier responsable de las cuentas y la administración junto al contralor, que estimaba cuáles eran las mejores mercancías y precios.

Gentiles hombres de boca se consideraban el comprador, sumiller de la panetería, sumiller del cava, ujier, cocineros, escuyer de cocina, portador de cocina, portero de cocina guardamanger, potager, sausier y aguador. Todos ellos se encargaban de la alimentación y el servicio a la mesa de las infantas y damas. Asimismo, juntos a estos oficiales se hallaba un contingente personal encargado de las labores domésticas como las lavanderas, el tapicero, el cerero y el aposentador de palacio, encargados de la limpieza, conservación, distribución de los manteles, sillas, candeleros y leña.

En las etiquetas de 1579 ya no se menciona la figura del aya. La cámara era regida por la Camarera mayor que solía hacer las funciones de esta. A su amparo se encontraban las camareras, las dueñas de honor y retrete, las damas, las mozas, la lavandera de corp, los ujieres de cámara, los reposteros de camas, los barrenderos y demás mozos y ayudas de cada oficio. Estos se encargaban de sus cuidados personales y el mantenimiento de la cámara. También eran importantes las visitas del médico, cirujano boticario y sangrador, quienes velaban por la salud de las infantas y de su personal. 
CIERTOS ASPECTOS SOBRE SU ORIGEN, FORMACIÓN Y DIFUSIÓN

De su seguridad y la de sus damas eran responsables el portero de saleta, el guardamayor, el guardamenor de damas y portero de damas, los cuales permanecían a turnos en la puerta de su cámara y salvaguardaban el decoro y la decencia de las damas.

Diversos oficiales de manos se encargaban de su arreglo y engalanamiento personal: sastres, plateros, plumajeros, sombrereros, zapateros, etc., configuraban y construían la imagen regia y majestuosa de las infantas.

La capilla constaba de capellanes y mozos. A diferencia de la del rey y la de la reina, la capilla de las infantas era mucho más elemental en cuanto a su servicio y estructura. No contaba con limosnero mayor y los capellanes debían ser los mismos que los de la Casa del rey. Los gajes y raciones de los capellanes que servían a las infantas dependían entonces de la Casa del monarca y en sus libros se dejaba constancia de su servicio a ambas casas ${ }^{38}$.

Asimismo, la caballeriza, más reducida que la del rey, reina y el príncipe, estaba gobernada por un caballerizo responsable de los «cavallos, machos, literas, guarniciones y todo lo demas tocante a la cabelleriza de las dichas infantas», junto a dos acemileros, un cochero, cuatro lacayos y un mozo de la caballeriza.

A lo sumo, aunque estas ordenanzas fueron redactadas para regir el personal de las hijas de Felipe II, tras la muerte de Ana de Austria en 1580, es posible que sirvieran de guía para la Casa del príncipe. Según Martínez Millán a raíz del matrimonio de Catalina Micaela con el duque Carlos Manuel de Saboya, el 18 de marzo de 1585, la Casa de Isabel Clara Eugenia fue reorganizada y ese mismo año, el 19 de enero de 1585, la Casa del príncipe, hasta el momento vinculada a la de sus hermanas, se hizo independiente ${ }^{39}$. Este es un dato sumamente importante porque parece indicar que la Casa del príncipe fue integrada en la de las infantas ante la ausencia de una soberana.

Igualmente, es significativo señalar que antes de la marcha de la menor de las infantas, se redactó La orden que es nuestra voluntad que guarden los criados y criadas de la serenísima infanta doña Catalina mi muy chara y muy amada Hija en lo que toca a su servicio, uso y exercicio ${ }^{40}$, un manuscrito escrito en Barcelona, a 13 de junio de 1585 por su secretario Don Juan Idiáquez, que presentaba un contenido muy similar, como muy bien señala la historiadora M. ${ }^{a}$ José del Río Barredo, al que mostraban las etiquetas dictadas en 1575 para la Casa de la reina

38. Ibidem.

39. Martínez Millán, J. y Visceglia, M. A. (dirs.): La monarquía de Felipe III: la casa del rey. Madrid, 2008, p. 1064.

40. Ordenanzas y etiquetas que el rey Felipe II mandó se guardasen por los criados y criadas de la casa de la serenísima infanta doña Catalina; refrendado por su secretario de estado Martín Gaztelu. San Lorenzo de El Escorial, 31-XII-1575. Biblioteca del Palacio Real [en adelante BPR], sección Etiquetas, II/3127, fol. 59r-155v. 
Ana de Austria y a las que en 1579 se redactaron para «los Criados y Criadas de las serenísimas Infantas» ${ }^{41}$.

En ellas se determinaba «El estilo que ha de usar la infanta en forma del tratamiento con algunas personas de allá assí en hablar como escribir las veces que lo hiciere se dará memoria aparte de la qual se podía usar (...) acordando a su tiempo ${ }^{42}$, transcendiendo estas etiquetas de las reinas de la monarquía hispánica a otros territorios como el Ducado de Saboya.

Asimismo, las ordenanzas dictadas en 1579 para el servicio, uso y ejercicio de la Casa de Isabel Clara Eugenia y Catalina Micaela, se mantuvieron sin cambios desde la fecha, sirviendo de modelo para la Casa de las posteriores infantas e infantes de la Casa de Austria hasta finales del régimen moderno.

\subsection{Notas sobre su personal}

Diversos documentos conservados en los Archivos Generales de Palacio y de Simancas nos permiten conocer parte del personal que conformaba la Casa de Isabel Clara Eugenia y Catalina Micaela.

Los manuscritos revelan que en los primeros años de vida su Casa era muy elemental. Al poco de nacer Isabel Clara Eugenia y Catalina Micaela, se habilitó una pequeña Casa para sus cuidados dentro de la Casa de la reina, modificando levemente su estructura tanto desde el punto de vista espacial como del de la servidumbre ${ }^{43}$. Un documento relacionado con la administración del pan en la Casa de Isabel de Valois, con fecha de enero de 1568, muestra que las infantas y la reina compartieron gran parte de sus oficiales ${ }^{44}$.

De acuerdo a la Casa de Isabel de Valois, su servidumbre se dividía en dos grupos: los oficiales franceses, que viajaron a la corte española formando parte del séquito de la reina, y los castellanos, con Antonio de la Cueva, marqués de Ladrada al mando. A partir de la muerte de Isabel de Valois, Felipe II castellanizará casi por completo la Casa de la reina y las infantas hallándose dos tendencias: la del cardenal Espinosa, representada por el marqués de Ladrada, y la del secretario Martín de Gaztelu ${ }^{45}$.

Antonio de la Cueva fue mayordomo mayor de la Casa de las infantas desde 1566 hasta 1574, ostentando el principal cargo de la Casa, junto a la camarera

41. BNM, Mss. 18720/1.38.

42. Ibidem.

43. Rodríguez Salgado, op. cit., p. 58.

44. Casa de Isabel de Valois. Nómina del pan en cada un día del presente mes de enero de 1568 sea de distribuir en servicio de la reina nuestra señora y en su Casa. Archivo General de Simancas [en adelante AGS], Casa Real-Obras y Bosques, leg. 36, fol. 6.

45. Labrador Arroyo, F.: «La influencia de la Casa de Castilla...», op. cit., p. 12. 
CIERTOS ASPECTOS SOBRE SU ORIGEN, FORMACIÓN Y DIFUSIÓN

mayor, Elvira Carrillo, dueña de honor de la Casa de Isabel de Valois, a quien «a primeros de septiembre de 1566 se dio asiento de aya de la serenísima ynfanta doña Ysabel Clara Eugenia, con dos mill ducados de salario en cada un año que corren desde el dicho día en adelante» ${ }^{46}$ hasta 1567.

Ese año, María Enríquez de Toledo, duquesa de Alba y camarera mayor de Isabel de Valois, fue escogida aya de las niñas ${ }^{47}$. La elegida debía tener las cualidades necesarias para la crianza de las hijas del rey cuidando aquellos aspectos referentes a su alimentación, instrucción y educación.

Felipe II, que profesaba una ferviente confianza por la familia Alba, al servicio de la corte durante años, decidió confiarle este nombramiento a María Enríquez de Toledo, cuando decidió trasladar a Flandes al duque de Alba como gobernador. Así se rompía con la tradición de que el cargo de aya lo ostentase una viuda y se le otorgaba un estatus muy codiciado dentro del círculo cortesano.

Hasta 1570, la duquesa de Alba ejerció de camarera mayor y aya de las infantas, siendo el apoyo principal de las Isabel Clara Eugenia y Catalina Micaela hasta la llegada de Ana de Austria a la corte. Por recomendación de la emperatriz María, madre de su nueva esposa, a quien incomodaba la estrecha relación entre la duquesa y la reina Catalina de Médicis, Felipe II la destituyó como camarera y en su lugar nombró a la marquesa de Fromista. Habiendo sido rebajado su rango, María Enríquez de Toledo solicitó el favor del rey para ser retirada del puesto de aya y, desde entonces, fue sustituida por María Chacón, marquesa de Sandoval, que ocupó el cargo hasta su muerte en $1575^{48}$. En la década de los 80 , según un documento del Archivo General de Palacio fechado en 1581, Juana de Padilla era quien ostentaba los oficios de aya y camarera mayor de Isabel Clara Eugenia y Catalina Micaela ${ }^{49}$.

Conforme al protocolo, en sus primeros años, la Casa de las infantas constaba también de varias amas de cría. Según el embajador francés Forquevaux, la elección «la llevaban a cabo los médicos de cámara a partir de cincuenta damas escogidas de las mejores familias nobles e hidalgas, en cuya herencia no hubiera ni sangre mora, ni judía» ${ }^{50}$. En las cartas que este embajador francés le escribió a Catalina de Médicis, narra que cuando la infanta Isabel Clara Eugenia nació, para complacer

46. Casa real, Isabel de Valois e infantas, Cartas de pago de distintos criados reales. AGS, Casa Real - Obras y Bosques, leg. 40, fol. 6.

47. Amezúa y MAYo, op. cit., p. 426.

48. Márquez de la Plata y Ferrándiz, V. M.: Mujeres de acción en el Siglo de Oro. Madrid, 2006, pp. 316-317.

49. Quenta de las labores que yo doña María de Montoya labandera de sus Altezas e hecho para servicio de la sereníssima Ynfanta doña Isabel, en todo el año pasado de mill quinientos ochenta y uno. AGP, Sección Administrativa, leg. 5226, exp. 1.

50. Recogido por AmezÚa y Mayo, op. cit., p. 374. 
a un hombre de la corte, fue requerida «una dama de un pueblo cercano a Valsaín con tan mala suerte que al día y medio de ser elegida se le retiró la leche y, cuando Ana Fajardo, la camarera mayor que sustituyó la duquesa de Alba en Valsaín, se dio cuenta, la niña estaba muerta de hambre. Inmediatamente hicieron llamar a palacio a una de las tres nodrizas elegidas en un primer momento, Beatriz de Mendoza, que con veinticinco años gozaba de buena salud y una constitución vigorosa» 51 .

Tres nodrizas solían disponerse para su alimento. Son conocidas María de Oviedo, ama de la infanta Isabel Clara Eugenia, y María de Messa, la principal nodriza de Catalina Micaela durante los veintidós meses que fue amamantada ${ }^{52}$.

La mayoría de noticias acerca de los oficiales que formaron la Casa de las hijas de Felipe II datan de los años en los que vivió su madre con la que compartieron gran parte de su personal. Juana de Barahona ${ }^{53}$ y Luisa Mejía ${ }^{54}$ eran las dueñas de honor encargadas de «la rropa y pañales de las serenísimas infantas» ${ }^{55}$, junto a Brianda de Villacorta ${ }^{56}$, dueña de la Casa de Isabel de Valois desde $1560^{57}$.

También hay que destacar como mozas de cámara a Leonor de Vivanco, «moza de cámara de la serenísima infanta doña Ysabel Clara Eugenia desde primero de septiembre de 1566 en adelante» ${ }^{58}$ y dueña de retrete desde 1560 en el séquito de Isabel de Valois, e Isabel de Mendoza, dama también de la Casa de la reina.

Otras ayudas de Cámara como María Franca, criada de María de Oviedo, Catalina de Squivel, criada de Leonor de Vivanco, Isabel Vélez, criada de Isabel de Mendoza, dama también de la reina, María de Gaona, criada de Juana de Barahona y Catalina Sánchez, ayuda de barrendera de las criadas de la Casa de las infantas en $1567^{59}$.

Hacia 1566-1568, estaban al servicio de las infantas los reposteros de camas Hernando de Frías, Hernando Lucero, ujier de saleta de Isabel de Valois, y Rodrigo de Castro. El cocinero Pierre de Burgos, en su cargo desde el 18 de agosto de 1566. Los barrenderos Alonso de Valdivieso y Antonio Pérez. Los ujieres de saleta

51. Ibidem.

52. KusChe, M.: Retratos y retratadores. Alonso Sánchez Coello y sus competidores. Sofonisba Anguissola, Jorge de la Rúa y Rolán Moys. Madrid, 2003, p. 224.

53. Casa real, Isabel de Valois e infantas, Cartas de pago de distintos criados reales. AGS, Casa Real - Obras y Bosques, leg. 40, fol. 6. «Dueña que ha de ser contada desde 10 de octubre de 1567».

54. Ibidem. Dueña que «Ha de ser contada desde 11 de octubre de 1567».

55. Ibidem. Desde el año de 1567.

56. AMEZÚA y MAYO, op. cit., p. 392.

57. Rodríguez SAlgado, op. cit., p. 83.

58. Ibidem.

59. Cuentas de la Casa de Isabel de Valois de 1560 en adelante, AGS, Casa Real - Obras y Bosques, leg. 38; Casa real, Isabel de Valois e infantas, Gastos de las lavanderas Juliana Rabin y Beatriz de Rosa. AGS, Casa Real - Obras y Bosques, leg. 40, fol. 18. 
nombrados a primeros de enero de 1567, Diego de Olesa y Juan de Palacios quien ostentaba el mismo cargo en la Casa de la reina ${ }^{60}$.

Las cuentas también mencionan a la lavandera de corp, Juliana Rabin, en el cargo desde 1560 en la Casa del Isabel de Valois, al igual que la lavandera de boca Beatriz de Rosa y no como Juana de Flores, quien ejerció este oficio desde octubre de 1567 solo en la Casa de las infantas ${ }^{61}$. Otros oficiales de los que queda constancia son el dorador Juan Gutiérrez, estofador de sus cunas, el cerrajero, Diego de la Torre y el entallador, Diego de Corral ${ }^{62}$.

La Casa de las infantas, además de ocuparse de todas sus necesidades, las preparaba y salvaguardaba para parecer "princesas» del más alto abolengo. En ella se hallaban sastres, plateros, zapateros, plumajeros, cordoneros, bordadores y pellejeros, es decir, todas las personas que contribuían a construir su apariencia, cuidando todos los detalles de su vestimenta y adorno desde que eran pequeñas. Petronila Contreras, lavandera de la reina desde 1568, se encargó de elaborar sus pañales hasta 1580. El sastre francés Eduard de la Cat, al servicio de la monarca desde 1560, confeccionó muchos de sus vestidos, junto Ane Vespier, bordador desde 1560 hacia 1568. Pedro de Prado hizo los servicios de cordonero, Esteban de Balco de gorrero, Majean Dree de zapatero, Pedro de Antecana, de calcetero y Juan Tomás de alpargatero en $1569^{63}$.

De la creación de sus joyas y otros útiles para la Casa se encargaban los plateros Pedro de Buitrago, tirador de plata y oro hasta 1591, Juan Rodríguez, platero de plata, y Arnao Bergel, platero de oro que se mantuvo en el cargo hasta $1577^{64}$.

La Casa poseía maestros encargados de la instrucción de Isabel Clara Eugenia y Catalina Micaela en saberes propios de su rango y su condición femenina. Sofonisba Anguissola, célebre pintora italiana que viajó desde Francia formando parte del séquito de damas de Isabel de Valois, las ilustró en el arte del dibujo y pintura, y Francisco Martínez en música y arpa ${ }^{65}$.

60. Cuentas de la Casa de Isabel de Valois de 1560 en adelante. AGS, Casa Real - Obras y Bosques, leg. 38 .

61. Casa real, Isabel de Valois e infantas, Cartas de pago de distintos criados reales, AGS, Casa Real - Obras y Bosques, leg. 40, fol. 6.

62. Cuentas de la Casa de Isabel de Valois de 1560 en adelante, AGS, Casa Real - Obras y Bosques, leg. 38 .

63. Casa de Isabel de Valois. Cuentas de los vestidos de la casa de Isabel de Valois y de las infantas. AGS, Casa Real - Obras y Bosques, leg. 37, fol. 5.

64. Cuentas de la Casa de Isabel de Valois de 1560 en adelante, AGS, Casa Real - Obras y Bosques, leg. 38 .

65. Robledo Estaire, L.: «La música en la Casa de la Reina, Príncipe e Infantas», en Robledo Estaire, L., Bordas Ibáñez, C., Carreras, J. J. y Knighton, T. (autores y editores): Aspectos de la Cultura musical en la Corte de Felipe II. Madrid, 2000, pp. 195-212. 
A partir de 1568 se incorporaron también a la Casa, María de Guzmán, «moza de cámara de la serenísima infanta doña Catalina desde primero de marzo de 1568 en adelante ${ }^{66}$ y María de Alcocer, lavandera de la reina, pasaron a ocupar el puesto de mozas de cámara de las infantas ${ }^{67}$. Asimismo, otros oficiales de boca, que habían formado parte de la Casa de la reina Isabel de Valois, comenzaron a formar parte de la Casa de sus hijas. Es el caso de Joan Francés, panadero de sus altezas, Joan de Méndez, sumiller de la panetería, Jerónimo García, confitero y especiero, Diego de la Peña, oblier, Gonzalo Muñoz de Castañeda, sumiller de la cava, Juan Ruíz de Valdivieso, comprador de la Casa, Francisco de Montalbán, potajier, los hermanos Gil de Formanue, pasteleros, Joan de Rojas, sausier y conservador de la plata, Francisco de Salvatierra, aguador, Gaspar de Ávila, proveedor de cera, Joan de Colmenares, su distribuidor, Jacques Bobuse, boticario, Ramón Fabre y Tomás de Ras, mozos de tapicería. Junto a ellos cabe señalar al aposentador de damas, Joan del Castillo, y también a Francisco de Sepúlveda, furrier de la caballeriza ${ }^{68}$.

Cuando la reina murió el 3 de octubre de 1568, parte de su Casa se mantuvo al servicio de sus hijas. Muchos de sus oficiales siguieron ocupando los mismos cargos al servicio de Isabel Clara Eugenia y Catalina Micaela. De esta manera, la Casa de las infantas se convirtió eventualmente en una estructura independiente más amplia cuyas cuentas requerían ser revisadas. Para que el cobro de estos oficiales, que realizaban los mismo oficios, siguiera siendo el mismo y fuera justo y proporcional, al que se les dispensaba en tiempos de Isabel de Valois, se calculó el coste total de la Casa de la reina y se dedujo de esa cantidad el estipendio que las infantas recibían para poder mantenerlo. Con fecha de marzo de 1569 un sumario conservado en el Archivo General de Simancas, muestra que los honorarios de la Casa de la reina estaban fijados en 6.193.338 maravedíes al año y que de ese suma 2.975.295, maravedíes estaban destinadas al sustento de la Casa de las infantas, asignación que debía perdurar para que su mantenimiento fuera equitativo y similar al establecido cuando la reina aún vivía ${ }^{69}$.

A partir de los años 70, se observa en las cuentas de la Casa de Isabel Clara Eugenia y Catalina Micaela, la incorporación de muchos oficios de manos dedicados a construir su regia apariencia. En 1572, Pedro Torres fue nombrado plumajero de las infantas. René Geneli, sastre de las infantas desde 1568, se mantuvo al servi-

66. Casa real, Isabel de Valois e infantas, Cartas de pago de distintos criados reales. AGS, Casa Real - Obras y Bosques, leg. 40, fol. 6 .

67. Casa real, Isabel de Valois e infantas, Memoriales de servidores, órdenes de pago. AGS, Casa Real - Obras y Bosques, leg. 40, fol. 4.

68. Casa real, Isabel de Valois e infantas de 1567 a 1568. AGS, Casa Real - Obras y Bosques, leg. 82.

69. Casa real, Isabel de Valois, Cuentas de su Casa. AGS, Casa Real - Obras y Bosques, leg. 398, fols. 1-7. 
cio de la Casa hasta 1597. Junto a él, Francisco de Herreruela ejerció su oficio de sastre desde 1580 y también Bartolomé Domínguez, ya en $1588^{70}$. En 1579 figuran también Ana de Guevara, artífice de tocas hasta 1584, Felipe de Mármol, escofiador, cuyo cese se produce el mismo año, Catalina de Camargo, calcetera de las infantas hasta 1587, e Isabel de Tula, zapatera que se mantuvo en al servicio de Isabel Clara Eugenia hasta el año de $1597^{71}$.

De igual manera, a finales de la década de los 70 trabajaron en la Casa de las infantas Lucas Burgos, principal bordador desde 1578 hasta 1591, Luis Navarro ${ }^{72}$, pellejero hacía 1580-1596, Martín de San Juan ${ }^{73}$, guantero que aparece nombrado en las cuentas de la Casa de 1578 a 1581, y María de Montoya ${ }^{74}$, lavandera al servicio de la reina y las infantas, desde 1581 hasta 1597. Además, por estos años los documentos mencionan a Melchor Quero de León ${ }^{75}$, entallador entre 1580-1587, y a los plateros Francisco de Reinalte ${ }^{76}$, en 1582-1597, y Antonio de Villegas, hacia $1578-1581^{77}$.

Durante estos años también se fue renovando el cargo de mayordomo mayor. Antonio de la Cueva, mayordomo mayor de la reina y las infantas desde 1566, se mantuvo en el puesto hasta su muerte en 1574. Fue sucedido por Juan de la Cerda, IV duque de Medinacelli, hasta que desempeñó esta función hasta 1575. Ese año fue escogido para la mayordomía mayor Pedro Fajardo, III Marqués de los Vélez, sustituido en 1579 por Francisco Zapata y Cisneros, conde de Barajas, mayordomo mayor hasta $1585^{78}$. Este último, fue quien tuvo que organizar y supervisar el cumplimiento de las ordenanzas escritas en 1579 para la Casa de

70. Contabilidad, contaduría, tesorería, 1577-1970, Cuentas de sastres, 1563-1590. AGP, Sección Administrativa, leg. 5272, exp. 2.

71. Contabilidad, contaduria, tesorería, 1577-1970, Cuentas de tiradores de oro, 1563-1692. AGP, Sección Administrativa, leg. 5276, exp. 3.

72. Contabilidad, contaduría, tesorería, 1577-1970, Cuentas de manguiteros, peleteros o pellejeros, 1563-1692. AGP, Sección Administrativa, leg. 5246, exp. 5.

73. Contabilidad, contaduría, tesorería, 1577-1970, Cuentas de guanteros y perfumeros, 15631622. AGP, Sección Administrativa, leg. 5236, exp. 11.

74. Contabilidad, contaduría, tesorería, 1577-1970, Cuentas de costureras, modistas y encajeras. AGP, Sección Administrativa, leg. 5226, exp. 1.

75. Contabilidad, contaduría, tesorería, 1577-1970, Cuentas de ebanistas. AGP, Sección Administrativa, leg. 5231.

76. Contabilidad, contaduría, tesorería, 1577-1970, Cuentas de costureras, modistas y encajeras. AGP, Sección Administrativa, leg. 5226, exp. 1.

77. Casa real, Isabel de Valois. Inventario de los bienes muebles de la reina doña Isabel de lo que le encargo don Cristóbal de Oviedo por orden de don Antonio de la Cueva, 1569. AGS, Casa Real - Obras y Bosques, leg. 67.

78. Contabilidad, contaduría, tesorería, 1577-1970, Cuentas de ebanistas. AGP, Sección Administrativa, leg. 5231. Antonio de la Cueva fue mayordomo de 1566 hasta 1574, posteriormente le sucedió Juan de la Cerda, IV duque de Medinaceli hasta 1580 que lo sustituyó Francisco Zapata y Cisneros. 
las infantas, año en el que, según las fuentes, Pedro de Quevedo fue nombrado escribano de cámara hasta aproximadamente $1597^{79}$.

Tras celebrarse en 1585 el matrimonio de la infanta Catalina Micaela con Carlos Manuel, duque de Saboya, algunos de sus oficiales marcharon formando parte del séquito de la infanta Catalina Micaela, por lo que la Casa ahora de la infanta Isabel Clara Eugenia fue reorganizada. Juan de Zúñiga, Comendador Mayor de Castilla, fue nombrado mayordomo mayor. Solo ocupó un año este cargo un año. Al fallecer en 1586 fue sustituido por Gonzalo de Ávila, Marqués de Velada, quien ostentó la categoría de mayordomo mayor de la Casa de Isabel Clara Eugenia hasta su marcha a los Países Bajos en 1599. Según una cédula de 1587 «para librar lo necesario para el pago de la Casa de la Serenísima Infanta Doña Isabel», el marqués de Velada, Gonzalo de Ávila, ayo y mayordomo mayor del príncipe, fue nombrado mayordomo mayor de la Casa de la infanta Isabel Clara Eugenia, sucediendo así al conde de Barajas. En este momento, Julio Fernández de Espinosa, «Thessorero de la casa de la Serenísima Reyna doña ana», pasó a desempeñar este oficio en ambas Casas, así como los contadores mayores, Juan Bernardo y Juan López de Vivanco comenzaron hacerse cargo de su administración ${ }^{80}$.

De esta manera, aunque desde el 19 de enero de 1585 la Casa del príncipe ya no formaba parte de la de su hermana, hasta 1599 Isabel Clara Eugenia y Felipe compartieron algunos de sus oficiales ${ }^{81}$.

De los años 90 también se han hallado noticias de oficiales de la Casa de la infanta Isabel Clara Eugenia que ocuparon oficios menores, como bordadores, plateros y mercaderes. Las relaciones de cuentas de su personal mencionan a Jerónima de Ávila, bordadora hacia 1591-1597, Diego de Ormaza, bordador en 1595 y Juan de Burgos, bordador desde 1597 a $1599^{82}$. También a los plateros Alonso García y Luis Morales, ambos a disposición de la infanta, desde 1592 a 1597 aproximadamente, y Bernardo Valverde, mercader de la Casa hacia $1595^{83}$.

Isabel Clara Eugenia abandonó España convertida en gobernadora de los Países Bajos, tras su matrimonio, el 18 de abril de 1599, con el archiduque Alberto de Austria. A ella, igual que a su hermana, se les dispuso un séquito de damas para

79. Contabilidad, contaduría, tesorería, 1577-1970, Cuentas de calceteros. AGP, Sección Administrativa, leg. 5218, exp. 4.

80. Isabel Clara Eugenia: gastos de su casa, 1587. AGP, Sección Histórica, caja 81, exp. 9.

81. Obsérvese la relación de los oficios de la Casa de la Infanta y el príncipe en la tesis doctoral de: Albaladejo Martínez, M.: Apariencia y Representación de las infantas de España en la corte de Felipe II en TDR <http://hdl.handle.net/10803/83534>.

82. Contabilidad, contaduría, tesorería, 1577-1970, Cuentas de bordadores. AGP, Sección Administrativa, leg. 5214, exp. 2.

83. Contabilidad, contaduría, tesorería, 1577-1970, Cuentas de plateros y diamantistas, 15631599. AGP, Sección Administrativa, leg. 5261, exp. 1; Contabilidad, Contaduría, tesorería, 1577-1970, Cuentas del guardajoyas de palacio, 1590-1599. AGP, Sección Administrativa, leg. 904. 
acompañarlas. Sin embargo, y a diferencia con Catalina Micaela, Isabel Clara Eugenia no pudo mantener la reglamentación y organización de su Casa siguiendo el modelo de servicio de Castilla. Los Estados Generales, instaban a los archiduques de los Países Bajos y demás príncipes a mantener sus costumbres. De esta manera se les rogó que organizaran su «Casa con igual estructura y dimensión que la de los duques de Borgoña» ${ }^{84}$.

\section{Algunos aspectos de la etiqueta de la Casa de las infantas durante el REINADO DE LOS AUSTRIAS MAYORES}

La primera fuente en hacer referencia a la «Etiqueta que se ha de guardar en la Casa de SS. AA» ${ }^{85}$ con posterioridad a las ordenanzas dictadas en 1579 , se trata de una nota de protocolo remitida con motivo del fallecimiento de la reina Isabel de Borbón, el 6 de octubre de 1644. El objeto de esta era conocer los procedimientos llevados a cabo tras la muerte de la anterior soberana Margarita de Austria, y establecer el modo de actuación de la Casa de la infanta María Teresa.

Cada Casa tenía la responsabilidad de cubrir los gastos generados de los lutos o medios lutos por los miembros de la monarquía. En relación con la Casa de la infanta M. ${ }^{a}$ Teresa, se dejaba constancia de la costumbre que existía acerca de esta práctica con los fallecimientos de Isabel Clara Eugenia, los infantes Carlos, Fernando, la emperatriz María de Austria y el rey Felipe III a través del siguiente texto:

Con un resumen de los criados de S.A para que se les den los mismos lutos que a los de Su Maj. Por la muerte de la emperatriz (...) el contralor dice que por las certificaciones que se presentan por los criados de la serenísima Yfanta parece haberse librado las cantidades necesarias para dar medios lutos a los criados de la Reyna nuestra señora en las orass passadas de muerte de la serenísima infanta de Flandes y nuestros infantes don Carlos y don Fernando que están en el cielo $=\mathrm{Y}$ para los medios lutos que por la casa del Rey nuestro señor se mandaron dar se libro ajustadamente la que pareció necesario conforme la Real orden que dio don Gerónimo de la billafuente Zapata Guardajoyas= Y haviendo se las de dar a los criados de la serenísima Ynfanta los dichos medios lutos que pretenden tomara el ejecutarlo por la casa de la Reyna nuestra señora como también el pedir dinero necesario para ellos por cuenta haberse librado separadamente. Para medios lutos de criados de la Casa de su majestad de la Reyna nuestra señora ${ }^{86}$.

84. Martínez Millán, J. y Visceglia, M. A. (dirs.): La monarquía de Felipe III: la casa del rey, op. cit., p. 1082.

85. Etiqueta de la Casa de los infantes con ocasión de la muerte de la reina Isabel de Borbón. AGP, Sección Histórica, caja 81, exp. 14.

86. Etiqueta de la Casa de los infantes con ocasión de la muerte de Isabel de Borbón. AGP, Sección Histórica, caja 81, exp. 18. Este documento firmado en Madrid a 13 de septiembre de 1949 
No obstante, estando fijadas las ordenanzas y normas de las Casas de las infantas de Austria desde 1579, los documentos hallados en el Archivo General de palacio en relación a la Casa de las infantas manifiestan que las disposiciones y preocupaciones en torno a la Casa de las hijas de los monarcas Felipe III y Felipe IV, estaban relacionadas con la libranza de los pagos de manutención y sostén de su servicio y no con el protocolo efectuado.

De época de Felipe III se conserva un documento sobre algunas de las expensas de la Casa de su hija María Ana (1606-1666). Este escrito del rey, fechado en 17 de septiembre de 1610, se trata de una carta de pago a la Casa de la infanta, probablemente tras la estancia en el palacio ducal de Lerma de la reina con motivo del alumbramiento de la infanta Margarita, que nació en mayo de $1610^{87}$. El cardenal duque de Lerma, por mandato de Felipe III le escribió a don Fernando Páez de Castillejo, corregidor de la ciudad de Burgos, para que «el dinero que hubiere en poder del receptor del servicio de millones de la dicha ciudad y de su partido» le entregase a Castelmellor, mayordomo mayor de la reina Margarita, la cantidad de 2.000 ducados «para el gasto de la casa que entonces havia de quedar en la Villa de Lerma a la sereníssima ynfanta doña María ${ }^{88}$. Dicho pago fue entregado, según lo corrobora dicha cédula con fecha de 8 de febrero de 1619 .

De igual manera, otro documento parece indicar que, tras la muerte de la reina Margarita de Austria, existía una asignación de 400 ducados en plata para la cámara de la infanta María Teresa, según menciona Álvaro de Bazán, II Marqués de Santa Cruz y mayordomo mayor de Isabel de Borbón, en un escrito al rey que dice así:

Don Jerónimo de Águila tesorero de sus Altezas me ha dado quenta como tiene en su poder quatrocientos Ducados en plata para la cámara de la señora infante aquenta de sus ordinarios y para poderse entregar es forzoso orden de V. Mag señalándome persona a quien se entreguen A la Camarera o al Aya y asimismo a de ser servida V. Mag. De mandar que se haga cédula para que los pueda recibir como y de la manera que la tiene Don Fernando de Borja y el Marques de Mirabel en todo mandara V. Mag. Lo que más convenga (...) a 11 de febrero de $1644^{89}$.

A raíz del fallecimiento Isabel de Borbón, el 6 de octubre de 1644, comenzó la reorganización de la Casa de la infanta, que tenía entonces seis años. De los

pone de manifiesto que la formación de la Casa era algo complejo y lento, especialmente la reinserción de los oficios en una nueva Casa y la reordenación de esta.

87. Yañez, J. y Rodríguez Franco, N.: Memorias para la bistoria de don Felipe III, rey de España. Madrid, 1723, p. 301.

88. Etiqueta de la Casa de los infantes con ocasión de la muerte de la reina Isabel de Borbón. AGP, Sección Histórica, caja 81, exp. 11

89. Idem, caja 81, exp. 13. Dicho pago debía entregarse de la mismo forma que a Fernando de Borja, sumiller del príncipe Baltasar Carlos y al Marqués de Mirabel, su ayo. 
siete hijos que Felipe IV tuvo con la reina, solamente vivían María Teresa y el príncipe Baltasar Carlos, que tenía quince años. En estas fechas la Casa de Felipe IV se había independizado de la de su hermana. Según este documento, firmado en Madrid a 12 de junio de 1643, ya se había resuelto poner Casa al príncipe "por hallarse en edad para apartarle del quarto de la mugeres» ${ }^{90}$. Sin embargo, compartía parte de su servicio con su hermana, como manifiesta el texto anteriormente citado. También es lícito pensar que ante las negociaciones matrimoniales de Felipe IV con Mariana de Austria la organización de su Casa fue un asunto que preocupase al monarca. No obstante, hasta la llegada a la corte de la soberana hubo un transcurso de cinco años, 1644-1649, habiéndose encontrado en la sección administrativa del Archivo de General de Palacio solamente cédulas referentes a gastos puntuales de la Casa de la infanta durante ese tiempo.

La recesión económica que atravesaba España, vinculada a los conflictos políticos agravados en los años cuarenta, se vislumbraron en la suspensión de pagos a los empleados de la Casa de la infanta María Teresa. En la junta de bureo de 15 de febrero de 1647 los cocheros, pajes y mozos de la caballeriza de la infanta solicitan las raciones correspondientes a veinticinco meses, además de la posesión de ciertos efectos «en poder de Don Antonio de Obiedo y en particular un efecto en Málaga de ochenta mill Reales» que, según las noticias, «no se cobra por no haver quien lo mande» ${ }^{91}$.

El 25 de octubre, se solicita también en la junta de bureo, para Lorenza Lopez de San Juan y Domingo García de Lorena, criados de la infanta, 79.120 U 919 maravedíes y otros efectos que debían ser entregados al tesorero Simón de Alcántara en presencia del escribano de cámara, acordado por un tercio del año.

Hacía 1648 se estaba terminando de instaurar la Casa de la infanta María Teresa. El 1 de enero de ese año un documento certifica la solicitud realizada por el presidente de hacienda, Fernando Ruíz Contreras y por el duque de Nájera, contralor de la Casa de la infanta María Teresa para nombrar a Domingo Centurión, mayordomo mayor de la infanta y de la Casa de la reina. El texto dice así:

Haviéndonos juntado el Presidente de hazienda Don Fernando Ruíz Contreras y yo, con el contralor de la casa de la Infanta Nuestra Señora y secretario de dicho presidente para conferir y ajustar los medios que asegurasen las asistencias de la casa de su Alteza en este presente por accidentes que sobrevinieron al Marques del Monasterio a quien vuestra Majestad había nombrado como mayordomo de la casa de S. A. y para esta junta no pudo venir a ella a la hora señalada ni hacer esta junta en la forma que V. M. había mandado que porque los achaques del Marques no le

90. Casa del Principe Felipe IV. AGP, Sección Histórica, caja 113, exp. 8.

91. Etiqueta de la Casa de los infantes con ocasión de la muerte de la reina Isabel de Borbón. AGP, Sección Histórica, caja 81, exp. 18. 
permitirán tratar de negocios en largo tiempo y esta materia no admite dilación pareció a los de la junta que V. M se podría servir de nombrar en su lugar a Don Domingo Centurión por ser la persona que puede suplir para el mismo intento de que me ha parecido dar (...) a V. M para que mande lo que mande fuere de su mismo servicio ${ }^{92}$.

Pocas noticias existen sobre el personal de la Casa de la infanta María Teresa. Según Oliván Santaliestra, dieciocho damas y meninas son nombradas en una mascarada realizada en honor a la reina el 21 de diciembre de 1648, como parte de la Casa de María Teresa ${ }^{93}$.

Como marcaba la etiqueta, a la llegada de la soberana Mariana de Austria, la Casa de la infanta, infantes y príncipes formaban parte de la Casa de la reina, según las ordenanzas.

Pocos son los datos hallados en relación con la infanta a excepción de una nota de protocolo que señala la importancia del decoro y la moderación del personal femenino y masculino de la Casa de la infanta María Teresa en el servicio a la mesa. Dicha nota, mandada redactar por el monarca bajo el título «Etiqueta que se debe guardar cuando comen y cenan SS. AA. en $1650 »^{94}$, que dice así:

En todos los tiempos se a puesto particular cuydado y atención en el recato y decencia con que se debía estar en las ante Cámaras de los Infantes, particularmente a las Oras del comer y cenar ques quando puede haver alguna relación y por haver entendido que la ay en la de la Infante mi Hija me ha parecido ordenar que mientras comiere y cenare este en la antecámara el Mayordomo Semanero sin pasar a la pieza donde come A donde entraran los oficiales de voca para que allí salgan las Damas y Meninas a tomar la vianda como tengo ordenado a la camarera mayor se le advierta y pues habiéndose en esta forma (que debe ser) cada qual estará en el puesto que le tocare y mi hija será servida en la decencia que es justo llebose a su excelencia en primero de Junio de 1650. En Madrid a 19 de Marzo de $1650^{95}$.

Estos documentos revelan, por tanto, la persistencia de las costumbres y normas que se introdujeron en el reinado de Felipe II, una época importante desde el punto de vista de la reglamentación y organización de la Casa de la infanta de la monarquía hispánica, reflejo de un imperio en expansión y de una riqueza tal que sus sucesoras intentaron encarnar en tiempos de dificultades.

92. Ibidem.

93. Oliván Santaliestra, L.: Mariana de Austria en la encrucijada política del siglo XVII. Memoria para optar al grado de doctor, bajo la dirección de la doctora M. ${ }^{a}$ Victoria López-Cordón Cortezo, Madrid, 2006, p. 152.

94. Etiqueta de la Casa de los infantes con ocasión de la muerte de Isabel de Borbón. AGP, Sección Histórica, caja 81, exp. 16.

95. Ibidem. 


\section{Epílogo}

La instauración y reglamentación de la Casa de las hijas de Felipe II fue el resultado de la consolidación de la Casa de las reinas hispanas, un modelo de servicio gestado durante siglos, que tomó forma a lo largo del siglo Xvi, sirviendo como ejemplo para la Casa de Isabel Clara Eugenia y Catalina Micaela.

La importancia «estratégica» de princesas y reinas consortes era advertida por quienes las rodeaban, de ahí la necesidad de controlar su servidumbre ${ }^{96}$. Isabel Clara Eugenia y Catalina Micaela eran la esperanza sucesoria de Felipe II, cuyos descendientes varones demostraron una salud muy precaria. Es lógico entonces que Felipe II quisiera controlar el acceso a sus hijas y dotarlas de los cuidados y comodidades propios de su rango.

Cuando eran pequeñas, su Casa era una extensión de la Casa de la de la reina. Si bien, cuando alcanzaron cierta edad, su Casa se independizó, equiparando así su estatus al de otras princesas europeas. El largo tiempo que permanecieron en la corte propició la formación de una Casa propia.

La instauración de su etiqueta fue uno de los pasos fundamentales para organizar y establecer el control de esta institución. Siguiendo el modelo de servicio de la Casa de Castilla implantado en las Casas de las reinas hispanas, las ordenanzas de 1579 seguían la estructura y el modelo de servicio impuesto a través de las etiquetas de Casa de la reina Ana con fecha de 1575.

Fueron las primeras infantas en contar con un protocolo escrito para su servicio. Estas reglas determinaban los gajes y raciones de un personal muy numeroso cuyos nombres pueden conocerse a través de la compilación de documentos dispersos que hablan sobre sus gastos. Se trata de una tarea ardua, aún por completar dada la inexistencia un listado que determine la planta completa de la Casa de Isabel Clara Eugenia y Catalina Micaela, entorpecida por las numerosas modificaciones que se realizaron desde el punto de vista de su personal. Casadas a edades no muy tempranas, permanecieron más años que otras princesas en la corte asistiendo a diversos cambios en su servidumbre por fallecimientos $u$ otras razones.

Isabel Clara Eugenia y Catalina Micaela gozaron de multitud de privilegios y comodidades, según se aprecia en los documentos conservados en instituciones españolas de gran relevancia. Estos abren un sinfín de posibilidades y de líneas de investigación en torno a temas como la etiqueta, el personal, la economía y vida cotidiana de estas infantas y otras posteriores de su dinastía.

96. García Barranco, op. cit., pp. 106-107. 


\section{BiBLIOGRAFÍA}

AmezÚA y MAYO, A.: Isabel de Valois, reina de España (1546-1568): Estudio biográfico. Madrid, Gráficas Ultra, 1949, 3 vols.

BucETA, E.: Relación de la Junta convocada por Felipe II el 24 de febrero de 1579 para tratar de su pretensión a la Corona de Portugal. Alicante, Biblioteca Virtual Miguel de Cervantes, Edición digital a partir de Boletín de la Real Academia de la Historia, tomo 98, cuaderno II (abril-junio. 1931), 2011, pp. 655-664

ChecA, F: El Real Alcázar de Madrid. Dos siglos de arquitectura y coleccionismo en la corte de los reyes de España. Madrid, Comunidad de Madrid, 1994.

CRUZ Medina, V.: «Y porque sale la Reyna a senar acabo, que es mi semana de serbir: La vida en palacio de la Reina Ana, las infantas Isabel Clara Eugenia y Catalina Micaela en las cartas de Ana de Dietrichstein», en López-Cordón, M. V., Franco Rubio, G. A. y FERnÁNDEZ IZQUIERDO, F. (coords.): La reina Isabel y las reinas de España: realidad, modelos e imagen historiográfica. Madrid, 2005, pp. 427-446.

Díaz Valgoma, D.: Norma y ceremonia de las reinas de la Casa de Austria. Madrid, Escelicer, 1958.

Fernández de Córdova Miralles, A.: La Corte de Isabel I. Ritos y ceremonias de una reina (1474-1504). Madrid, Dykinson, 2002.

García Barranco, M.: «La Casa de la reina en tiempos de Isabel de Valois», Crónica Nova, 29, 2002, pp. 85-107.

Kusche, M.: Retratos y retratadores. Alonso Sánchez Coello y sus competidores. Sofonisba Anguissola, Jorge de la Rúa y Rolán Moys. Madrid, Fundación de Apoyo a la Historia del Arte Hispánico, 2003.

Labrador Arroyo, F. y López Álvarez, A.: «Las caballerizas de las Reinas en la Monarquía de los Austria: cambios institucionales y evolución de las etiquetas, 1559-1611», Studia Historica. Historia Moderna, 28, 2006, pp. 87-140.

LABRADOR ARROYO, F.: «La evolución del servicio de la mesa en la casa de las reinas hispanas durante el siglo XVI» en MERLOTTI, A.: Le tavole di corte tra cinque e settecento. Torino, 2013, pp. 125-150.

LABrador Arroyo, F.: «La influencia de la Casa de Castilla en la organización de la Casa de las Reinas hispanas» en GAmbra GuTiÉRrez, A. y LABrador ARroyo, F. (coords.): Evolución y estructura de la casa real de Castilla. Madrid, 2010, pp. 227- 262.

López NieTo, F.: Honores y protocolo. Madrid, Ed. El Consultor de los Ayuntamientos y de los Juzgados, 2006.

Márquez de la Plata y Ferrándiz, V. M.: Mujeres de acción en el Siglo de Oro. Madrid, Castalia, 2006.

MARTínez Millán, J. y LourençO, M. ${ }^{2}$ P. M. (coords.): Las relaciones discretas entre las Monarquias hispana y portuguesa. Las Casas de las Reinas (siglos XV-XIX). Madrid, Polifemo, 2009.

Martínez Millán, J. y Visceglia, M. A. (dirs.): La monarquía de Felipe III: la casa del rey. Madrid, Mapfre, 2008. 
Martínez Millán, J. y Fernández Conti, S.: La monarquía de Felipe II: la Casa del Rey. Madrid, Mapfre, 2005.

RAE: Diccionario de Autoridades. Madrid, Edición Facsímile, 1990.

Río BARREDO DEL, M. J.: «De Madrid a Turín: el ceremonial de las reinas españolas en la Corte ducal de Catalina Micaela de Saboya», Cuadernos de Historia Moderna, Anejo II. Madrid, 2003, pp. 97-122;

Robledo Estaire, L.: «La música en la Casa de la Reina, Príncipe e Infantas», en Robledo Estaire, L., Bordas IbáÑEZ, C., CARreras, J. J. y Knighton, T. (autores y editores): Aspectos de la Cultura musical en la Corte de Felipe II. Madrid, 2000, pp. 195-212.

Rodríguez SAlgado, M. J.: «Isabel de Valois. Casa y vida de una perfecta princesa», Cuadernos de Historia Moderna, 28, 2003, pp. 85-107.

VAN WyHe, C.: Isabel Clara Eugenia. Soberanía femenina en las cortes de Madrid y Bruselas. Madrid, Centro Estudios Europa Hispánica, 2011.

YÁÑEZ, J. y Rodríguez Franco, N.: Memorias para la historia de don Felipe III, rey de España. Madrid, 1723. 